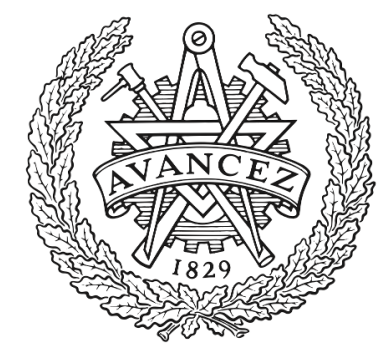

\title{
CHALMERS
}

UNIVERSITY OF TECHNOLOGY

\section{A GapWaveguide-Fed Wideband Patch Antenna Array for 60-GHz Applications}

Downloaded from: https://research.chalmers.se, 2023-04-26 13:12 UTC

Citation for the original published paper (version of record):

Zarifi, D., Farahbakhsh, A., Uz Zaman, A. (2017). A GapWaveguide-Fed Wideband Patch Antenna Array for 60-GHz Applications. IEEE Transactions on Antennas and Propagation, 65(9): 4875-4879. http://dx.doi.org/10.1109/tap.2017.2722866

N.B. When citing this work, cite the original published paper.

(O2017 IEEE. Personal use of this material is permitted.

However, permission to reprint/republish this material for advertising or promotional purposes 


\section{A Gap Waveguide-Fed Wideband Patch Antenna Array for 60-GHz Applications}

\author{
Davoud Zarifi, Ali Farahbakhsh and Ashraf Uz Zaman
}

\begin{abstract}
This communication presents a wideband aperturecoupled patch antenna array based on Ridge Gap Waveguide (RGW) feed layer for 60-GHz applications. The novelty of this antenna lies in the combination of relatively new gap waveguide technology along with conventional patch antenna arrays allowing to achieve a wideband patch antenna array with high gain and high radiation efficiency. An 8×8-element array antenna is designed, fabricated and tested. Experimental results show that the bandwidth of VSWR $<2.0$ is up to $15.5 \%(57.5-67.2$ GHz). More than $75 \%$ efficiency and higher than $21.5 \mathrm{dBi}$ gain are achieved over the operational bandwidth. The results are valuable for the design and evaluation of wideband planar antenna arrays at millimeter-wave frequencies.
\end{abstract}

Index Terms - Patch antenna, planar arrays, gap waveguide technology.

\section{INTRODUCTION}

In recent years, there has been an increase in the development of millimeter-wave wireless communication systems at $60 \mathrm{GHz}$ band due to the demand of high-data-rate short-range wireless communication [1]. The main challenge of the $60 \mathrm{GHz}$ band is very high radio wave absorption caused by the resonance of oxygen molecules. One candidate as a solving method is using high gain antennas with high radiation efficiency.

Development of high-gain wideband millimeter-wave antenna arrays with high radiation efficiency has attracted increasing attention in the recent years. Different planar antenna arrays, such as microstrip and substrate-integrated waveguide (SIW) arrays and slot antenna arrays are the two main technologies for millimeter-wave applications [2-6]. The low efficiency of the large microstrip and SIW antenna arrays brings a lot of restrictions to their practical millimeter wave applications. One major aspect restricting the achievable gain of these antenna arrays is the losses in feeding networks. In fact, realizing a high-gain array antenna in the millimeterwave band requires a low-loss feeding network. As common candidates, corporate-feed waveguide slot arrays have been used to achieve high gain and efficiency. At high frequencies, these antennas require accurate, high precision and expensive manufacturing [7]. Recently, the gap waveguide technology has been introduced and used in [8-10]. In this technology, the waveguide can be realized without any requirement of metal contact between the upper metal surface and the lower surface. This simplifies the mechanical assembly of the designed antennas and hence reduces the production cost for the antennas. To date, some wideband high gain and efficiency

D. Zarifi is with the School of Electrical Engineering, University of Kashan, Kashan, Iran. A. Farahbakhsh is with the School of Engineering, Graduate University of Advanced Technology, Kerman, Iran. A. U. Zaman is with the Department of Signals and Systems, Chalmers University of Technology, SE-412 96 Göteborg, Sweden (e-mail:zarifi@kashanu.ac.ir; a_farahbakhsh@iust.ac.ir; zaman@chalmers.se) array antennas have been realized based on gap waveguide technology in different frequency ranges [11-17]. Also, the gap technology can be used for RF packaging which makes it possible to integrate the RF electronics with the gap waveguide antennas [18-19].

In this communication, aperture-coupled microstrip antenna arrays fed by ridge gap waveguide (RGW) feed networks are investigated at $60-\mathrm{GHz}$ band. An Array of 64 radiating elements is designed and simulated. The main advantage compared to other reported gap waveguide based planar arrays is that this structure can keep a two layer planar profile compared with three layers slot arrays included feed network, cavity layer and radiating slots layer [12, 13]. Also, the dimensions of the proposed $2 \times 2$-element sub-array are $4.9 \mathrm{~mm}$ $\left(0.98 \lambda_{0}\right) \times 4.9 \mathrm{~mm}\left(0.98 \lambda_{0}\right)$ which are smaller than $8.8 \mathrm{~mm}$ $\left(1.76 \lambda_{0}\right) \times 8.8 \mathrm{~mm}\left(1.76 \lambda_{0}\right)$ [13] allowing limited range of scanning if needed. The simulation and measurement results show that the proposed array has high gain and efficiency for $60 \mathrm{GHz}$ applications. The metal feed network can be easily manufactured by Computer Numerical Control (CNC) milling, moulding or by electric discharge machining.

The communication is organized as follows. Section II deals with the design of $2 \times 2$-element sub-array, feeding network, $8 \times 8$-element antenna array and the transition from RGW to WR-15. The performances of the antenna array are discussed in Section III and the simulation and measurement results are presented. Finally, Section IV provides a conclusion.

\section{ANTENNA DESIGN AND ANALYSIS}

This section describes the design procedure and the simulation results of the antenna sub-array and complete array. The simulations are performed using the full-wave electromagnetic simulator CST MWS.

\section{A. 2×2-Element Sub-array}

The configuration of $2 \times 2$-element sub-array is depicted in Fig. 1. It consists of a dielectric layer, a patch layer and a RGW feed layer. Patches are metallic rectangles of $1.6 \mathrm{~mm} \times$ $1.25 \mathrm{~mm}$ on a Duroid 6002 substrate $\left(\varepsilon_{r}=2.94\right.$, loss tangent $=$ 0.0012 and thickness $=0.254 \mathrm{~mm}$.). Two copper layers are on the opposite sides of the substrate with the thickness of the metal layers $18 \mu \mathrm{m}$. The center to center spacing between adjacent patch elements is $2.45 \mathrm{~mm}\left(0.49 \lambda_{0}\right.$ at $\left.60 \mathrm{GHz}\right)$ in both $x$ and $y$ directions. Thus, the problems associated with grating lobes will be much smaller than for the other gap waveguide slot array antennas $[12,13]$.

The microstrip patch is a narrow band resonant structure. There are many available techniques to enhance the bandwidth of microstrip patch antennas. Here, to expand the bandwidth, a coupling slot is used to feed center feed line of patches. Aperture coupled feed provides a greater radiation pattern symmetry and greater ease of design for larger impedance band width owing to a large number of design parameters. A wideband $2 \times 2$ patch antenna with SIW based aperture coupled feed has been proposed in [20] for W-band applications from 91-97 GHz (6.4\% bandwidth). In our case, we use the topology of microstrip $\mathrm{T}$-junctions to divide power with microstrip $\mathrm{T}$-junctions to divide power with wideband characteristic. Thus a wider range of impedance matching is 


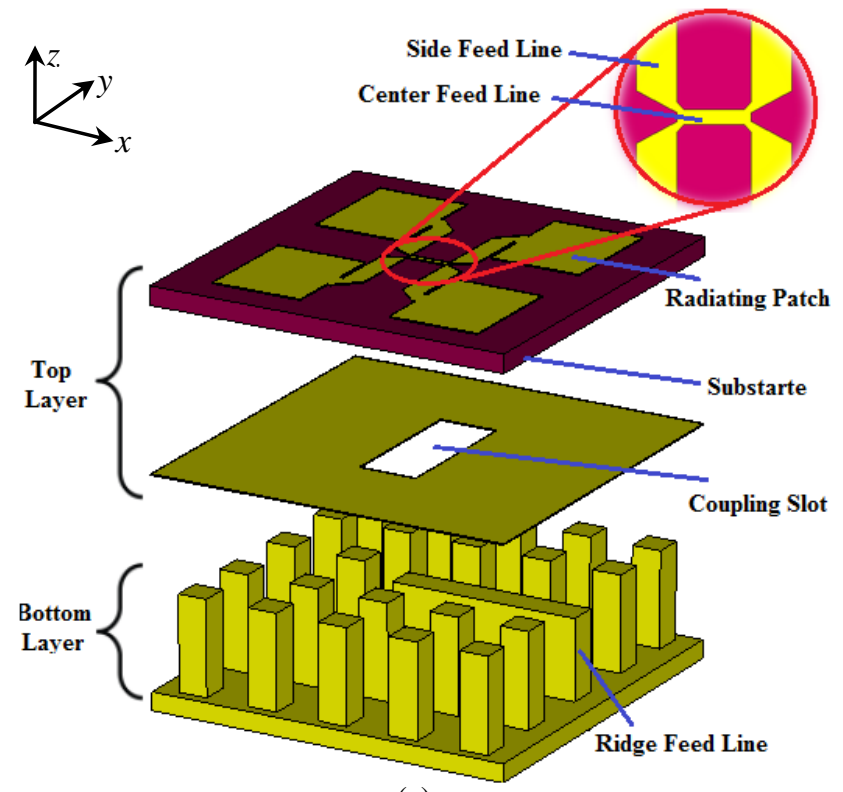

(a)

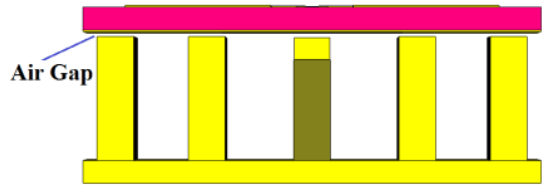

(b)

Fig. 1. 2×2-element sub-array. (a) Exploded view. (b) Side view.

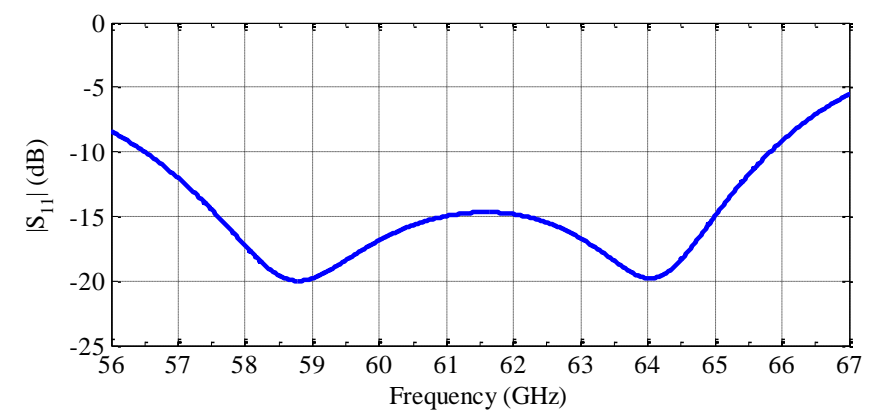

Fig. 2. Simulated reflection coefficient of proposed $2 \times 2$-element sub-array

achieved by proper design of the length and width of the aperture and width of center line feed.

The lower layer contains some metal pins and a ridge forming a RGW distribution network. Periodic metal pins are planted on both sides of the ridge to produce desired stop-band characteristics and to prevent wave propagation in unwanted directions. Based on $[12,13]$, the dimensions of pins are chosen to achieve a cut-off bandwidth from 40 to $100 \mathrm{GHz}$. As shown in Fig. 1(b) there is a small air gap between the top surface of pins and conducting plane so there is no requirement for electrical contact between them. The RGW feed structure excites the coupling slot etched in the ground plane of the substrate. By optimizing the dimensions of coupling slots and microstrip feed lines, four patches can be excited with same amplitude and phase [20]. This is performed by using optimization in CST to achieve acceptable matching and radiation properties. Notice that four radiating patches have the same phases and amplitudes of the E-field, which shows the sub-array has a maximum in the broadside.

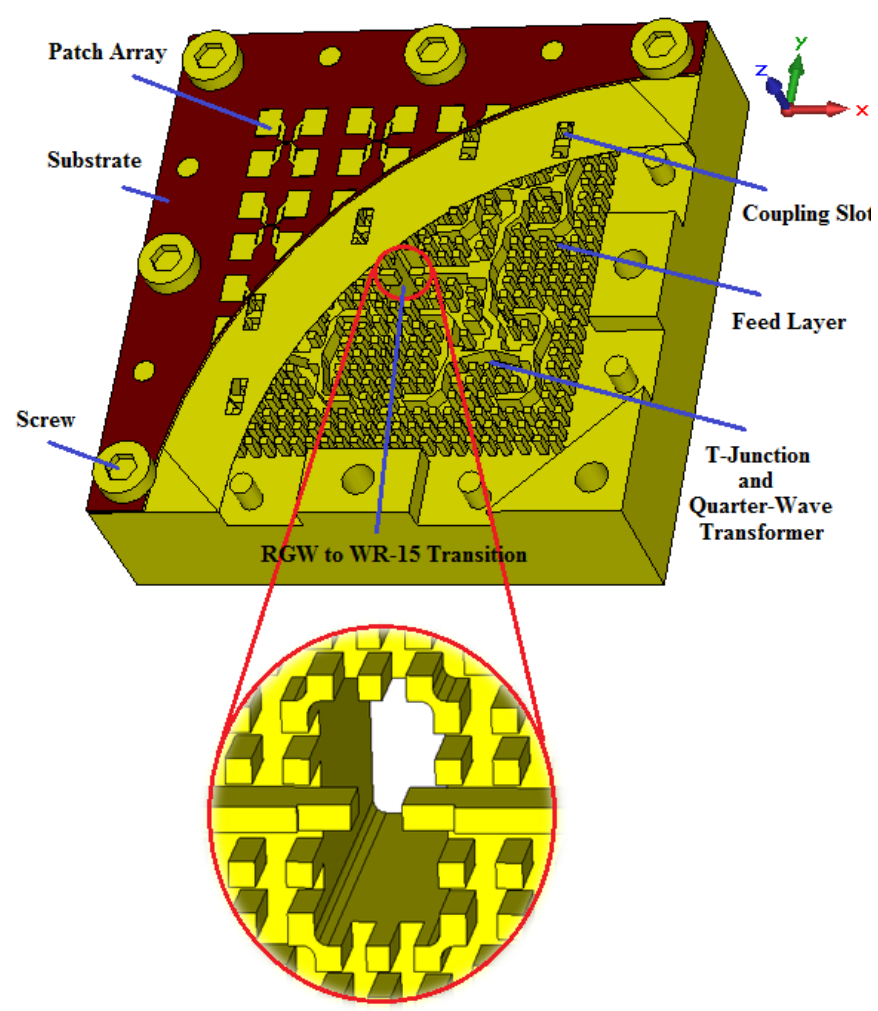

Fig. 3.Perspective view of $8 \times 8$-element patch antenna array.

The designed sub-array has $4.9 \times 4.9 \mathrm{~mm}^{2}$ dimensions in $x$ and $y$ directions. The mutual coupling between sub-arrays is automatically included by using the infinite array approach. As shown in Fig. 2, the simulated reflection coefficient of the sub-array shows the bandwidth of 56.5-66 GHz (15.5\%)for $|S 11|<-10 \mathrm{~dB}$.

For high gain applications, an array with $8 \times 8$-patch antenna array is designed as shown in Fig. 3.The corporate feed network is realized by interconnecting $\mathrm{T}$-junction power dividers. In lower layer, a RGW power divider is designed to feed upper 64 radiating patches uniformly by 16 rectangular coupling slots. The feeding network is based on the quarterwave impedance transformers and matched T-junctions. The detailed design of different power dividers based on RGW technology has been discussed in [13].

For the purpose of measurement, a wideband and compact transition between WR-15 and RWG is designed, as shown in Fig. 3. Observe that at the end of the ridges, two steps are used, which makes the mode of RGW transform to the $\mathrm{TE}_{10}$ mode of rectangular waveguide. The transition is designed and optimized for minimum reflection and insertion loss in the operating frequency band.

Notice that due to the differential outputs provided by the transition in two ridges, left hand side and right side of the feed layer are mirrored. The input power to rectangular waveguide excites the antenna by the designed transition and then flows through a RGW 16-way power divider. For achieving the desired matching, all the parameters of the transition, power divider and microstrip structure are optimized. The detailed optimal dimensions of the proposed antenna array are given in Table I. 
TABle I. Design PARAMETERS OF $8 \times 8$-ELEMENT ARRAY

\begin{tabular}{|c|c|c|}
\hline Component & Parameter & Value (mm) \\
\hline Radiating Patches & $\begin{array}{c}\text { Length } \\
\text { Width } \\
\text { Center to center space } \\
\text { Width of side feed lines } \\
\text { Width of center feed line } \\
\text { Larger Length of T- Junction } \\
\text { Smaller Length of T- Junction }\end{array}$ & $\begin{array}{c}1.6 \\
1.25 \\
2.45 \\
0.3 \\
0.1 \\
0.35 \\
0.06\end{array}$ \\
\hline Pins & Dimensions & $0.4 \times 0.4 \times 1.3$ \\
\hline Ridge & $\begin{array}{l}\text { Height } \\
\text { Width }\end{array}$ & $\begin{array}{l}1.1 \\
0.4\end{array}$ \\
\hline T-Junctions & $\begin{array}{l}\text { Larger Length } \\
\text { Smaller Length }\end{array}$ & $\begin{array}{c}3 \\
0.3\end{array}$ \\
\hline $\begin{array}{l}\text { Quarter-wave } \\
\text { Transformers }\end{array}$ & $\begin{array}{l}\text { Length } \\
\text { Width }\end{array}$ & $\begin{array}{l}0.65 \\
0.93\end{array}$ \\
\hline Air Gap & height & 0.05 \\
\hline Coupling Slots & $\begin{array}{l}\text { Length } \\
\text { Width }\end{array}$ & $\begin{array}{c}2 \\
0.8\end{array}$ \\
\hline $\begin{array}{l}\text { RGW to WR-15 } \\
\text { Transition }\end{array}$ & $\begin{array}{l}\text { Length of Step } \\
\text { Height of Step }\end{array}$ & $\begin{array}{c}0.8 \\
0.14\end{array}$ \\
\hline
\end{tabular}

\section{SimUlation AND EXPERIMENTAL RESUltS}

To verify the simulated results, a prototype of the designed patch antenna array was fabricated by standard CNC milling techniques, which is exhibited in Fig. 4.To verify the antenna operation experimentally, the antenna was fed by a standard rectangular waveguide. Measurements on $\mathrm{S}_{11}$, gain, and radiation patterns were performed by a millimeter-wave band vector Network Analyzer in an outdoor test range measurement system.

The simulated and measured input reflection coefficients of the antenna array are shown in Fig. 5. The measured bandwidth for $|S 11|<-10 \mathrm{~dB}$ is $15.5 \%$ from 57.5 to $67.2 \mathrm{GHz}$. The differences between the measured and the simulated results are because of the tolerances of manufacturing and assembling tolerances.

Fig. 6 shows the frequency behavior of the simulated directivity and measured gain, as well as the aperture efficiency. However, there is less than $1 \mathrm{~dB}$ difference between the measured gain and simulated directivity results. This discrepancy results partially from deviation of the dielectric and metallic losses in simulation and the measurement setup and also the tolerance of the fabricated antenna. Still the total radiation efficiency of the antenna array is higher than $75 \%$ over the operating frequency band. The difference between simulated and measured values $60-61 \mathrm{GHz}$ is due to measurement uncertainty which is considered to be $\pm 0.25 \mathrm{~dB}$ or approximately $0.5 \mathrm{~dB}$ using standard gain horn in out measurement chamber.

Fig. 7 shows the simulated and measured normalized radiation patterns at 58 and 62 and $67 \mathrm{GHz}$ in both E- and $\mathrm{H}$ planes. The main reason of the small difference is measurement uncertainty. The measured radiation patterns

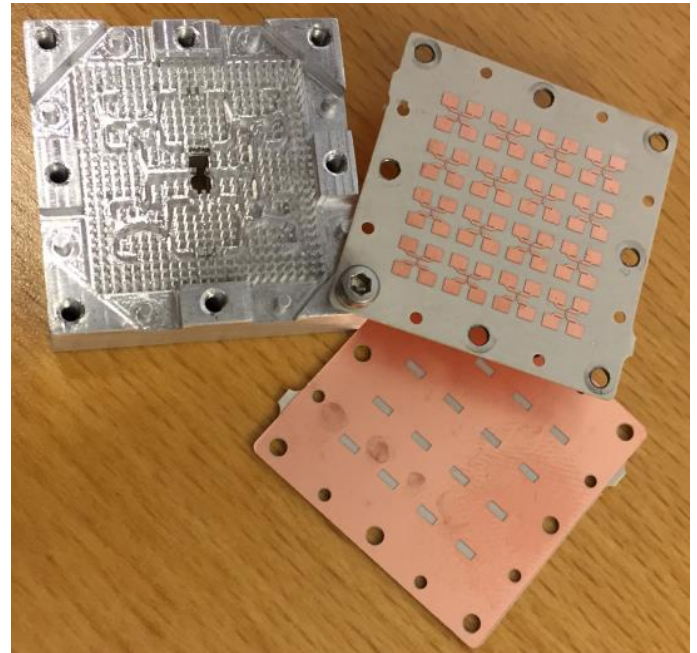

Fig. 4. Photograph of fabricated antenna. The structure has dimension of $28 \times 28 \times 7 \mathrm{~mm}^{3}$.

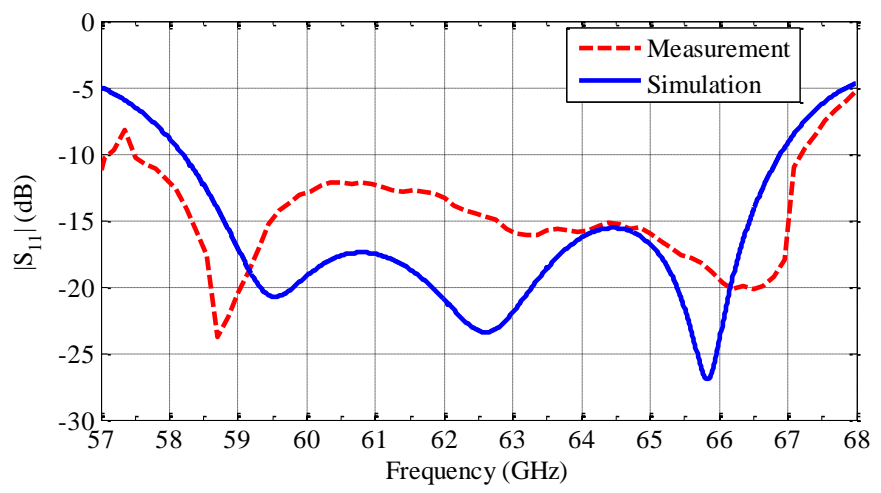

Fig. 5.Simulated and measured $\left|S_{11}\right|$ of $8 \times 8$-element patch antenna array.

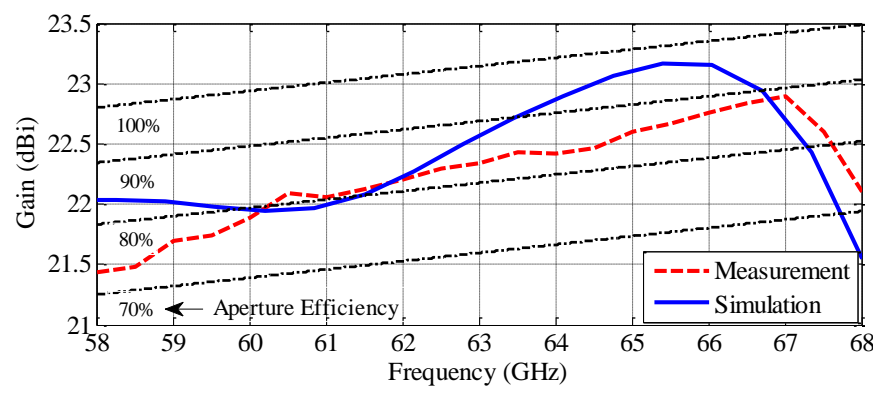

Fig. 6. Simulated directivity and measured gain of $8 \times 8$-element array antenna and $100 \%, 90 \%, 80 \%$ and $70 \%$ efficiency lines.

with 3-dB beamwidth at $62 \mathrm{GHz}$ are around $13^{\circ}$ and $15^{\circ}$ in Eand $\mathrm{H}$-planes, respectively. Also, the measured maximum sidelobe level at $62 \mathrm{GHz}$ is $-13.5 \mathrm{~dB}$ and the front-to-back ratio is better than $25 \mathrm{~dB}$. In addition, the measured crosspolarization level of the antenna is detected as $-28 \mathrm{~dB}$ at the boresight.

In Table II, we compare our work with different published $60-\mathrm{GHz}$ antenna arrays and we summarize the findings in terms of bandwidth, realized gain and efficiency (gain/ $D_{\text {uniform}}$ ). Observe that the efficiency of our RGW fed patch antenna array is higher than those of the proposed arrays in [2- 


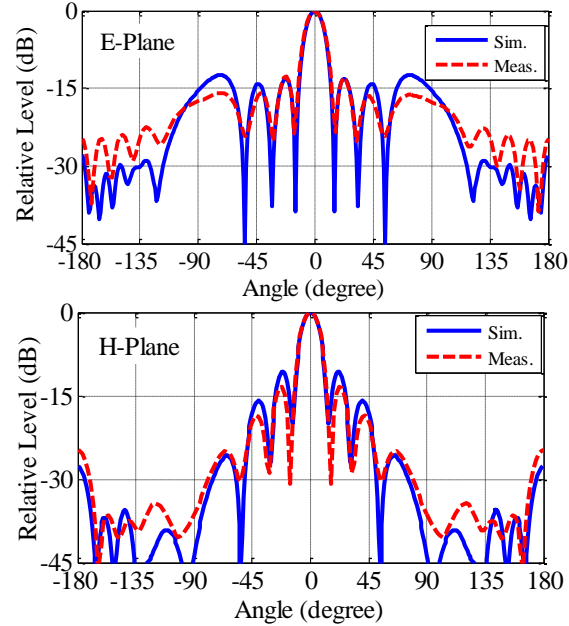

(a)
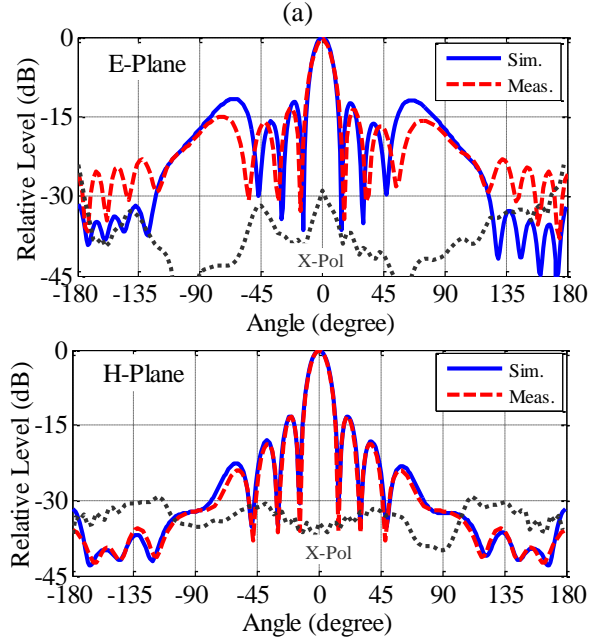

(b)
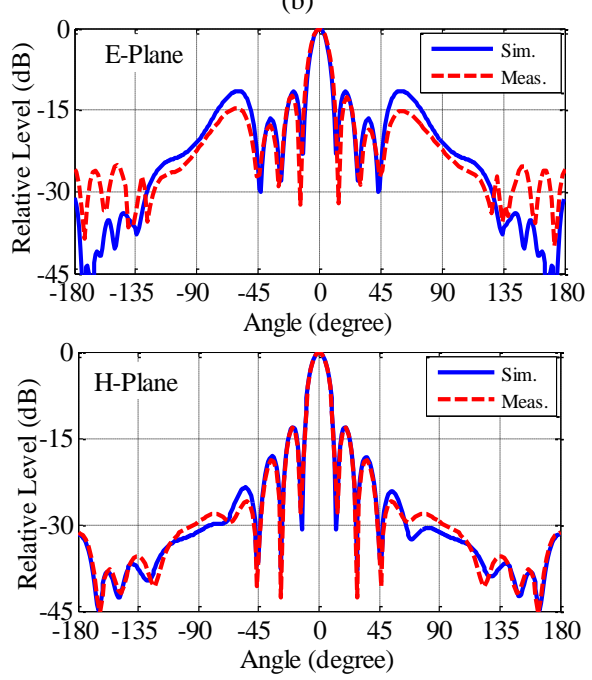

(c)

Fig. 7. Simulated and measured radiation patterns of the $8 \times 8$-element array. (a) $58 \mathrm{GHz}$, (b) $62 \mathrm{GHz}$, (c) $67 \mathrm{GHz}$.

5]. This is mainly due to the absence of the dielectric loss in the feeding network of antenna array. In addition, the proposed antenna array can keep a two layer planar profile compared with other three layers RGW slot arrays [12, 13].
TABLE II.COMPARISON BETWEEN PROPOSED AND REPORTED 60-GHZ PLANAR ANTENNA ARRAYS

\begin{tabular}{|c|c|c|c|c|c|c|}
\hline & Our work & {$[12]$} & {$[2]$} & {$[3]$} & {$[4]$} & {$[5]$} \\
\hline $\begin{array}{c}\text { Aperture } \\
\text { Size }\left(\mathrm{mm}^{2}\right)\end{array}$ & $19.6 \times 19.6$ & $32 \times 32$ & $20 \times 15$ & $35 \times 34$ & $47 \times 31$ & $35 \times 31$ \\
\hline $\begin{array}{c}\text { Number of } \\
\text { Elements }\end{array}$ & 64 & 256 & 16 & 64 & 64 & 64 \\
\hline $\begin{array}{c}\text { Frequency } \\
(\mathrm{GHz})\end{array}$ & $57.5-67.2$ & $56.2-65$ & $55-68$ & $56.3-65.7$ & $54.7-65.1$ & $57.5-67$ \\
\hline $\begin{array}{c}\text { Bandwidth(\%) } \\
\mid \text { S11|<-10 dB }\end{array}$ & 15.5 & 14 & 21 & 15.4 & 17 & 14.1 \\
\hline $\begin{array}{c}\text { Gain (dBi) } \\
\text { Efficiency } \\
(\%)\end{array}$ & $21.5-23$ & $24.7-26$ & $12.8-15.6$ & $21.2-24.2$ & $20-22.1$ & $<26$ \\
\hline $\begin{array}{c}\text { Technology } \\
\text { Waveguide }\end{array}$ & $\begin{array}{c}\text { Waveguide } \\
\text { Gap-80 }\end{array}$ & $58-70$ & $40-42$ & 44.5 & $60-68.5$ \\
\hline $\begin{array}{c}\text { Number of } \\
\text { Layers }\end{array}$ & 2 & 3 & 1 & 2 & 3 & 3 \\
\hline
\end{tabular}

\section{CONCLUSIONS}

An $8 \times 8$-element patch array antenna fed by RGW was proposed in this communication. The simulation results have been verified by measuring a fabricated prototype of the proposed antenna array. Experimental results showed satisfactory agreement with the simulation. At the operation frequency $(57.5-67.2 \mathrm{GHz})$, the fabricated prototype has an impedance bandwidth of $15.5 \%$ for a reflection coefficient lower than $-10 \mathrm{~dB}$, a gain of higher than $21.5 \mathrm{dBi}$, and a sidelobe level below $-13 \mathrm{~dB}$ in both $\mathrm{E}-$ and H-planes. The proposed antenna array fed by RGW could be utilized in a wide range of applications where microstrip antennas are usually used.

\section{ACKNOWLEDGMENT}

The authors would like to gratefully acknowledge late Prof. Per-Simon Kildal from Chalmers University, Sweden for his sincere support during this work. He passed away unexpectedly before this paper could be submitted for review. Many of the ideas and concepts presented in this paper have been stimulated after several meetings and discussion with him.

The work has been supported by the European Research Council (ERC) via an advanced investigator grant ERC-2012ADG 20120216, and by the VINNOVA smart electronics program with the project grant 2015-01387.

\section{REFERENCES}

[1] P. Smulders, "Exploiting the $60 \mathrm{GHz}$ band for local wireless multimedia access: Prospects and future directions," IEEE Commun. Mag.vol. 40, no. 1, pp. 140-147, Jan. 2002.

[2] W. Yang, K. Ma, K. S. Yeo, and W. M. Lim, "A Compact HighPerformance Patch Antenna Array for $60-\mathrm{GHz}$ Applications," IEEE 
Antennas and Wireless Propagation Lett., vol. 15, pp. 313-316, Feb. 2016.

[3] W. Liu, Z. N. Chen, and X. Qing, "60-GHz thin broadband high-gain LTCC metamaterial-mushroom antenna array," IEEE Trans. Antennas Propag. , vol. 62, no. 9, pp. 4592-4601, Sep. 2014.

[4] J. F. Xu, Z. N. Chen, X. M. Qing, and W. Hong, "Bandwidth enhancement for a $60 \mathrm{GHz}$ substrate integrated waveguide fed cavity array antenna on LTCC," IEEE Trans. Antennas Progag., vol. 59, no. 3, pp. 826-832, Mar.2011.

[5] J. Wu, Y. J. Cheng, Y. Fan, "60-GHz substrate integrated waveguide fed cavity-backed aperture-coupled microstrip patch antenna array," IEEE Trans. Antennas Propag., vol. 63, no. 3,pp. 1075-1085, March 2015.

[6] D. Kim, M. Zhang, J. Hirokawa, andM. Ando, "Design and fabrication of a dual-polarization waveguide slot array antenna with high isolation and high antenna efficiency for the $60 \mathrm{GHz}$ band," IEEE Trans. Antennas Propag. , vol. 62, no. 6, pp. 3019-3027, June 2014.

[7] Y. Miura, J. Hirokawa, M. Ando, Y. Shibuya, and G. Yoshida, "Doublelayer full-corporate-feed hollow-waveguide slot array antenna in the 60 GHz-band," IEEE Trans. Antennas Propag., vol. 59, no. 8, pp. 2844 2851, Aug. 2011.

[8] P.-S. Kildal, E. Alfonso, A. Valero-Nogueira, and E. Rajo-Iglesias, "Local metamaterial-based waveguides in gaps between parallel metal plates," IEEE Antennas Wireless Propag. Lett., vol. 8, pp. 84-87, 2009.

[9] P.-S. Kildal, "Three metamaterial-based gap waveguides between parallel metal plates for $\mathrm{mm} / \mathrm{submm}$ waves," in Proc. 3rd Eur. Conf. Antennas Propag., Berlin, Mar. 2009.

[10] P.-S. Kildal, A. U. Zaman, E. Rajo-Iglesias, E. Alfonso, and A. ValeroNogueira, "Design and experimental verification of ridge gap waveguides in bed of nails for parallel plate mode suppression," IETMicrow., Antennas Propag., vol. 5, no. 3, pp. 262-270, Mar. 2011.

[11] A. Razavi, P.-S. Kildal, X. Liangliang, E. Alfonso, and H. Chen, "2x2slot Element for $60 \mathrm{GHz}$ Planar Array Antenna Realized on Two Doubled-sided PCBs Using SIW Cavity and EBG-type Soft Surface fed by Microstrip-Ridge Gap Waveguide," IEEE Trans. Antennas Propag. , vol. 62 , no. 9 , pp. 4564-4573, Sep. 2014.
[12] A. Vosoogh and P. S. Kildal, "Corporate-Fed Planar $60 \mathrm{GHz}$ Slot Array Made of Three Unconnected Metal Layers Using AMC pin surface for the Gap Waveguide," IEEE Antenna Wireless Propagation Letter., vol. 15, pp. 1935-1938, 2016.

[13] D. Zarifi, A. Farahbakhsh, A. U. Zaman and P. S. Kildal, "Design and Fabrication of A High-Gain $60 \mathrm{GHz}$ Corrugated Slot Antenna Array with Ridge Gap Waveguide Distribution Layer," IEEE Trans. Antennas Propag., vol. 64, no. 7, pp. 2905-2913, July 2016.

[14] A. U. Zaman and P. S. Kildal, "Wide-Band Slot Antenna Arrays With Single-Layer Corporate-Feed Network in Ridge Gap Waveguide Technology," IEEE Trans. Antennas Propag., vol. 62, no. 6, pp. 29923001, June 2014.

[15] B. Cao, H. Wang and Y. Huang, "W-Band High-Gain TE 220 -Mode Slot Antenna Array With Gap Waveguide Feeding Network," IEEE Antennas and Wireless Propagation Letters, vol. 15, no. , pp. 988-991, 2016.

[16] M. Al Sharkawy and A. A. Kishk, "Wideband Beam-Scanning Circularly Polarized Inclined Slots Using Ridge Gap Waveguide," in IEEE Antennas and Wireless Propagation Letters, vol. 13, no., pp. 1187-1190, 2014.

[17] A. Jiménez Sáez, A. Valero-Nogueira, J. I. Herranz and B. Bernardo, "Single-Layer Cavity-Backed Slot Array Fed by Groove Gap Waveguide," IEEE Antennas and Wireless Propagation Letters, vol. 15, no. , pp. 1402-1405, 2016.

[18] Zhang, X. Zhang, D. Shen and K. Wu, "Gap Waveguide PMC Packaging for a SIW-GCPW-Based Filter," IEEE Microwave and Wireless Components Letters, vol. 26, no. 3, pp. 159-161, March 2016.

[19] A. U. Zaman, V. Vassilev, P. S. Kildal and H. Zirath, "Millimeter Wave E-Plane Transition From Waveguide to Microstrip Line With Large Substrate Size Related to MMIC Integration," IEEE Microwave and Wireless Components Letters, vol. 26, no. 7, pp. 481-483, July 2016.

[20] Y. J. Cheng, Y. X. Guo, and Z. Q. Liu, "W-Band large-scale high-gain planar integrated antenna array," IEEE Trans. Antennas Propag., vol. 62, no. 6, pp. 3370-3373, Jun. 2014. 